\title{
CUGC for Stromme syndrome and CENPF-related disorders
}

\author{
Isabel Filges $\mathbb{1}^{1} \cdot$ Petter Stromme ${ }^{2}$
}

Received: 18 May 2019 / Revised: 16 July 2019 / Accepted: 2 August 2019 / Published online: 5 September 2019

(c) European Society of Human Genetics 2019

\section{Disease characteristics}

\subsection{Name of the disease (synonyms)}

Stromme syndrome

Jejunal atresia with microcephaly and ocular anomalies.

Apple peel syndrome with microcephaly and ocular anomalies.

Ciliopathy phenotype.

Primary microcephaly and intellectual disability.

\subsection{OMIM\# of the disease}

243605.

\subsection{Name of the analysed genes or DNA/ chromosome segments}

CENPF.

\subsection{OMIM\# of the gene(s)}

600236.

\subsection{Mutational spectrum}

Data according to published literature and HGMD database (https://portal.biobase-international.com).

Exact figures of genotype-phenotype correlations and the full mutational spectrum of $C E N P F$-related disorders are

Isabel Filges

Isabel.Filges@unibas.ch

1 Medical Genetics, Institute of Medical Genetics and Pathology and Department of Clinical Research, University Hospital Basel and University of Basel, Basel, Switzerland

2 Division of Pediatric and Adolescent Medicine, Oslo University Hospital, University of Oslo, Oslo, Norway still hard to provide. The phenotypes range from isolated primary microcephaly, the clinical triad of Stromme syndrome including microcephaly, ocular anomalies and intestinal atresia to a variable ciliopathy phenotype including brain anomalies (such as hydrocephalus, cerebellar hypoplasia, agenesis of the corpus callosum), cleft palate, polydactyly, renal dysplasia and duodenal/intestinal atresia, which may be fetal lethal at the severe end of the spectrum [1-7]. Inheritance is autosomal recessive and all variants affecting function in affected individuals described to date are truncating variants (nonsense/stop, splice site, deletion and insertion sequence variants) $[1-3,8-10]$.

\subsection{Analytical methods}

Sequencing of all coding exons and intron-exon boundaries of $C E N P F$ by Sanger sequencing, or using next generation sequencing (NGS) for gene panel testing for Mendelian syndromes including ciliopathy panels or panels for microcephaly, ocular anomalies or intestinal anomalies, or by exome or genome sequencing.

\subsection{Analytical validation}

Sanger sequencing is predicted to detect $>99 \%$ of variants of this known gene. Variants potentially affecting function are bidirectionally sequenced in the index patient. Segregation analysis in the parents of the index patient should be performed to ensure compound heterozygosity or homozygosity. For NGS methods, sensitivity will depend on the characteristics of the test, including coverage of the coding regions and intron-exon boundaries, read depth and sequencing quality. Variants of unknown significance are possible.

\subsection{Estimated frequency of the disease}

(Incidence at birth ("birth prevalence") or population prevalence. If known to be variable between ethnic groups, please report). 
Unknown, but the prevalence is estimated to be rare $(<1: 1,000,000)$.

\subsection{Diagnostic setting}

\begin{tabular}{lll} 
& Yes. & No. \\
A. (Differential) diagnostics & $\bigotimes$ & $\square$ \\
B. Predictive Testing & $\square$ & $\square$ \\
C. Risk assessment in Relatives & $\bigotimes$ & $\square$ \\
D. Prenatal & $\bigotimes$ & $\square$ \\
\hline
\end{tabular}

Comment:

\section{Test characteristics}

\begin{tabular}{|c|c|c|}
\hline $\begin{array}{l}\text { Genotype or } \\
\text { disease }\end{array}$ & A: True positives & $\mathrm{C}$ : False negative \\
\hline Present Abs & : False positives & D: True negative \\
\hline
\end{tabular}
Test

\begin{tabular}{|c|c|c|c|}
\hline Pos. A & B & $\begin{array}{l}\text { Sensitivity: } \\
\text { Specificity: }\end{array}$ & $\begin{array}{l}\mathrm{A} /(\mathrm{A}+\mathrm{C}) \\
\mathrm{D} /(\mathrm{D}+\mathrm{B})\end{array}$ \\
\hline
\end{tabular}

Neg. C D Pos. predict. value: $A /(A+B)$

Neg. predict. value: $\mathrm{D} /(\mathrm{C}+\mathrm{D})$

\subsection{Analytical sensitivity}

(proportion of positive tests if the genotype is present) Nearly $100 \%$.

\subsection{Analytical specificity}

(proportion of negative tests if the genotype is not present)

Nearly $100 \%$.

\subsection{Clinical sensitivity}

(proportion of positive tests if the disease is present)

The clinical sensitivity can be dependent on variable factors such as age or family history. In such cases a general statement should be given, even if a quantification can only be made case by case.

The clinical sensitivity is not known so far, but may depend on the clinical phenotype. For a typical clinical presentation of Stromme syndrome sensitivity may be very high, also for the presence of intestinal atresia associated with anomalies of the ciliopathy spectrum, although we cannot exclude genetic heterogeneity to date. For patients with isolated microcephaly, intellectual disability or more unspecific ciliopathy phenotypes clinical sensitivity is expected to be much lower since there is well-established and extensive genetic heterogeneity for these disorders.

\subsection{Clinical specificity}

(proportion of negative tests if the disease is not present)

The clinical specificity can depend on variable factors such as age or family history. In such cases a general statement should be given, even if a quantification can only be made case by case.

If the disease is not present, no variants affecting function should be found in $C E N P F$ and thus clinical specificity should be $100 \%$.

\subsection{Positive clinical predictive value}

(life time risk to develop the disease if the test is positive) $100 \%$.

\subsection{Negative clinical predictive value}

(probability not to develop the disease if the test is negative)

Assume an increased risk based on family history for a non-affected person. Allelic and locus heterogeneity may need to be considered.

Index case in that family had been tested:

$100 \%$ if there are proven variants affecting function in the index case.

Index case in that family had not been tested:

This depends on whether the clinical diagnosis in the proband is correct. If a confident clinical diagnosis has been made in the index patient and since clinical signs are usually present at birth, the negative clinical predictive value would be expected to be high. Milder phenotypic presentations as e.g. postnatal microcephaly may escape clinical detection.

\section{Clinical utility}

\section{1 (Differential) diagnostics: The tested person is clinically affected}

(To be answered if in 1.9 "A" was marked) 


\subsubsection{Can a diagnosis be made other than through a genetic test?}

No. $\square$ (continue with 3.1.4)

Yes. $\triangle$ in typical phenotype presentations clinically.

imaging.

endoscopy.

biochemistry.

electrophysiology.

other (please describe):

\subsubsection{Describe the burden of alternative diagnostic methods to the patient}

The diagnosis of Stromme syndrome can be made on clinical grounds alone, however, diagnostic imaging will make a contribution to diagnosis and is necessary for surgical treatment of intestinal atresia. Success of the latter will define survival. Brain MRI for the characterization of brain and ocular anomalies and clinical assessment of a pediatric neurologist and ophthalmologist will be necessary. The clinical presentation of other $C E N P F$-related disorders may be more unspecific since there is extended clinical and genetic heterogeneity for these phenotypes. Screening for associated anomalies including brain MRI, echocardiography, and abdominal ultrasound is mandatory to narrow the differential diagnoses and for further medical management. Chromosomal microarray should be considered to exclude causal copy number variants. Except for brain MRI, for which sedation in children in often needed, all other diagnostic measures have a low burden for patients, but the need for surgical intervention due to intestinal anomaly is significant.

Whenever prenatal ultrasound detects a fetal anomaly of the $C E N P F$-disorder spectrum, specialist fetal anomaly scan and eventually fetal MRI is indicated. A certain proportion of foetuses and patients will have a lethal outcome.

\subsubsection{How is the cost effectiveness of alternative diagnostic methods to be judged?}

Clinical work-up and imaging may be less cost-intensive, however, may not lead to the specific diagnosis if the phenotype presentation is not distinctive for Stromme syndrome.
3.1.4 Will disease management be influenced by the result of a genetic test?

No.

Yes. $\otimes$

Therapy

(please describe)

Prognosis

(please describe)

Management

(please describe)

diagnosis of Stromme syndrome or a $C E N P F$-related disorder has important implications for management. Intestinal surgery is life-saving, if successful, and knowledge of the diagnosis should prompt ophthalmological and neurodevelopmental evaluation in an affected child and early interventions in order to improve the long-term individual outcome. Early prenatal diagnosis and/or preimplantation genetic diagnosis become possible in the family. 
3.2 Predictive Setting: The tested person is clinically unaffected but carries an increased risk based on family history

(To be answered if in 1.9 "B" was marked)

3.2.1 Will the result of a genetic test influence lifestyle and prevention?

If the test result is positive (please describe) not applicable

If the test result is negative (please describe) not applicable

3.2.2 Which options in view of lifestyle and prevention does a person at-risk have if no genetic test has been done (please describe)?

Not applicable.

\subsection{Genetic risk assessment in family members of a diseased person}

(To be answered if in 1.9 "C" was marked).

\subsubsection{Does the result of a genetic test resolve the genetic situation in that family?}

Yes. If compound heterozygous or homozygous variants affecting function are identified in the index patient, carrier testing can be offered to other family members as appropriate. Reproductive options such as prenatal diagnosis or preimplantation genetic diagnosis can be offered to carrier parents.

3.3.2 Can a genetic test in the index patient save genetic or other tests in family members?

Yes. Carrier testing or prenatal or preimplantation genetic diagnosis can only be offered when the causal variants have been identified in the index patient.

3.3.3 Does a positive genetic test result in the index patient enable a predictive test in a family member?

No.

\subsection{Prenatal diagnosis}

(To be answered if in 1.9 "D" was marked)
3.4.1 Does a positive genetic test result in the index patient enable a prenatal diagnosis?

Yes. Parents of an affected child have a $25 \%$ recurrence risk for each further pregnancy. Early prenatal diagnosis by chorionic villous sampling or preimplantation genetic testing using targeted molecular testing of the familial variants affecting function is enabled by a positive genetic test result in the index patient. Targeted non-invasive prenatal testing using the paternal variant may become a screening option in the future in at risk families.

\section{If applicable, further consequences of testing}

Please assume that the result of a genetic test has no immediate medical consequences. Is there any evidence that a genetic test is nevertheless useful for the patient or his/her relatives? (Please describe)

Reproductive options such as early prenatal diagnosis or preimplantation genetic diagnosis become available as well as carrier testing of at risk family members. Counseling about phenotype variability and associated variable outcomes in affected individuals is important.

Acknowledgements This work was supported by EuroGentest2 (Unit 2: "Genetic testing as part of health care"), a Coordination Action under FP7 (Grant Agreement Number 261469) and the European Society of Human Genetics. Scientific work of IF is supported by the Swiss National Science Foundation (SNSF), Project (320030_160200).

\section{Compliance with ethical standards}

Conflict of interest The authors declare that they have no conflict of interest.

Publisher's note: Springer Nature remains neutral with regard to jurisdictional claims in published maps and institutional affiliations.

\section{References}

1. Waters AM, Asfahani R, Carroll P, Bicknell L, Lescai F, Bright A et al. The kinetochore protein CENPF is mutated in human ciliopathy and microcephaly phenotypes. J Med Gen. 2015;52:147-56.

2. Filges I, Bruder E, Brandal K, Meier S, Undlien DE, Waage TR et al. Stromme syndrome is a ciliary disorder caused by mutations in CENPF. Hum Mutat. 2016;37(4):359-63.

3. Ozkinay F, Atik T, Isik E, Gormez Z, Sagiroglu M, Sahin OA et al. A further family of Stromme syndrome carrying a CENPF mutation. Am J Med Gen A. 2017;173(6):1668-72.

4. Castori M, Laino L, Briganti V, Pedace L, Zampini A, Marconi M et al. Jejunal atresia and anterior chamber anomalies: further delineation of the Stromme syndrome. Eur J Med Gen. 2010;53 (3):149-52. 
5. Van Bever Y, van Hest L, Wolfs R, Tibboel D, van den Hoonaard TL, Gischler SJ. Exclusion of a PAX6, FOXC1, PITX2, and MYCN mutation in another patient with apple peel intestinal atresia, ocular anomalies and microcephaly and review of the literature. Am J Med Gen A. 2008;146A:500-4.

6. Stromme P, Dahl E, Flage T, Stene-Johansen H. Apple peel intestinal atresia in siblings with ocular anomalies and microcephaly. Clin Genet. 1993;44:208-10.

7. Stromme P, Anderson W. Developmental aspects in apple peel intestinal atresia-ocular anomalies-microcephaly syndrome. Clin Genet. 1997;52:133.
8. Kahrizi K, Hu H, Hosseini M, Kalscheuer VM, Fattahi Z, Beheshtian $\mathrm{M}$ et al. Effect of inbreeding on intellectual disability revisited by trio sequencing. Clin Genet. 2019;95:151-9.

9. Maddirevula S, Alzahrani F, Al-Owain M, Al Muhaizea MA, Kayyali HR, AlHashem A et al. Autozygome and high throughput confirmation of disease genes candidacy. Gen Med. 2019;21:736-42.

10. Meier N, Bruder E, Lapaire O, Hoesli I, Kang A, Hench J et al. Exome sequencing of fetal anomaly syndromes: novel phenotype-genotype discoveries. Eur J Hum Genet. 2019;27(5): $730-7$. 